\title{
Can mirrors beat the greenhouse?
}

People should not personally assume responsibility for the greenhouse effect, which would be impossible, but they should give some thought to the quantities involved.

Among the green community, the prospect that the excess greenhouse effect may be a reality, even here and now, has evoked a general wish to be seen to be doing something to assist in its abatement. That is natural enough, even though there are the strongest possible reasons for suspecting that individual virtue will serve only to provide the less virtuous with a licence not to follow suit, which is why the proper regulation of the greenhouse requires an international convention. Meanwhile, a child's guide to some of the steps that individuals might take may also serve as a guide to the underlying simple arithmetic.

At the present average distance between the Sun and the Earth, the solar energy flux normal to the line of sight is roughly $1,370 \mathrm{~W} \mathrm{~m}^{-2}$, but only some 70 per cent of that reaches the surface of the Earth. (Ultraviolet is mostly absorbed by the ozone layer, which is mostly still there, radio waves are screened out by the ionosphere and so on.) The average sub-zenith solar flux may be taken as 950 $\mathrm{W} \mathrm{\textrm {m } ^ { - 2 }}$, not very different from $1 \mathrm{~kW} \mathrm{~m}^{-2}$, but that is only ever nearly valid in the tropics, while half of the surface of the Earth is always turned away from the Sun; the average flux at the surface is therefore one quarter of the sub-zenith flux, say $240 \mathrm{~W} \mathrm{~m}^{-2}$.

It is important that the mismatch between incoming and outgoing radiation fluxes expected from the accumulation of $\mathrm{CO}_{2}$ and other greenhouse gases is of the order of $1 \mathrm{~W} \mathrm{~m}^{-2}$. This, for example, is the degree of what is called in the trade the 'forcing' of the Earth's climate system caused by the accumulation of $\mathrm{CO}_{2}$ and, to a lesser extent, of methane, between 1850 and 1960 - then the only greenhouse gases worth talking of. (CFCs have become a serious contributor to the problem only since that time.) People bent on personal steps to ameliorate the excess greenhouse effect must keep that figure in mind. What can they do?

First, perhaps, they should consider what might be done with simple mirrors. If one happened to live in the tropics, one might hope that a square metre of silvered glass placed in one's back garden would reflect back to space a substantial fraction of the incident flux of energy - perhaps not the whole of $1 \mathrm{~kW}$, but roughly a quarter of it. But even that is not quite true. When the mirror surface is away from the sub-zenith point, the absorption and scattering of energy on the longer pathways into and out of the atmosphere will be greater. Perhaps the most one can hope for is that an eighth of $1 \mathrm{~kW} \mathrm{~m}^{-2}$ will on the average be turned away.

Naturally it is worse when, like most people, one lives outside the tropics. Then there is an extra factor of $\cos \alpha$ (where $\alpha$ is latitude) to be taken account of, as well as the extra absorption and scattering in the atmosphere. At latitude $60^{\circ}$, that means a further factor of two on account of latitude, and yet another factor of two on account of extra path length through the atmosphere. If the albedo of the part of the surface on which the silvered mirror is placed is that of a perfectly absorbing black body (which cannot be exactly true), a single square metre of silvered surface will turn back only an average of roughly $30 \mathrm{~W}$. Carpeting a few per cent of the Earth's surface with mirrors would be necessary to counteract the greenhouse forcing so far (which emphasizes why snow cover and sea ice are important in climate models). But an area smaller by a factor of about four would be required in the tropics.

Absolute quantities are important at this stage. In round numbers, the surface area of the Earth (two-thirds of which is water) is $5 \times 10^{14} \mathrm{~m}^{2}$, which means that the greenhouse forcing of the past 150 years is the equivalent of $5 \times 10^{5} \mathrm{GW}$ of energy not very different from the world's present production of electricity.

Even if one takes the view that one's personal responsibility is limited to one's fair share, it would still be necessary, if repairing past damage is the goal, to be personally responsible for returning to space the equivalent of $100 \mathrm{~kW}$ of solar energy, requiring an investment in some $3,000 \mathrm{~m}^{2}$ of mirror surface outside the tropics or in something like $750 \mathrm{~m}^{2}$ in the Sahara. If, on the other hand, one took the view that it would suffice to neutralize by mirrors one's incremental contribution to the excess greenhouse effect, then because the next fifty years are expected to be about as damaging as the past 150 it would suffice to lay $150 \mathrm{~m}^{2}$ of one's nontropical back garden with mirror surface every year, or to arrange that an agent acting on one's behalf in the Sahara similarly treats $20 \mathrm{~m}^{2}$ or so of desert surface every year.

This argument is a reductio ad absur$d u m$, and is meant to be. (Most people do not have back gardens that big, in any case.) But the orders of magnitude are important. The calculated imbalance between the incoming and the outgoing radiation is of the order of a few $\mathrm{kW}$ per person now alive. It must surely be relevant that most of the $5 \times 10^{9}$ of us do not have the opportunity to consume that much electricity.

The opportunity for a technical fix arises at this point. The green community naturally abhors technical fixes, often on the grounds that they are palliatives rather than permanent 'solutions', but it should not go unremarked that the most economical solution of the greenhouse problem by means of mirrors must be that lightweight mirrors, no doubt made of aluminium foil, should be installed in the line of sight between here and the Sun.

No doubt there would be countless opportunities for endlessly more sophisticated calculations of the effects of radiation pressure on such structures. There have already been several calculations in the past of how such devices might be used to channel solar energy towards collecting stations on the surface of the Earth. Faced with the contemporary version of the problem - how best to get rid of solar energy - the space research community would no doubt be able to rise to the challenge.

That is why the true essence of the greenhouse problem is not the question of whether the concentration of $\mathrm{CO}_{2}$ in the atmosphere is increasing (it is), or that of the degree to which CFCs are more important as greenhouse gases than $\mathrm{CO}_{2}$, but that of how the accumulation of these materials in the atmosphere will affect the average temperature on the surface of the Earth and then, more subtly, the climate.

So the responsibility falls upon the shoulders of the modellers. What is the coefficent relating $\mathrm{CO}_{2}$ concentration to the average temperature on the surface of the Earth? The second is evidently a function of the first, and the function is to a first approximation linear, at least when the processes are slow enough, so there must be a number relating one to another. The role of that number is not to tell us whether or not we should be concerned, but to help us to decide whether we should stay awake at nights. But such a challenge is hopelessly premature: the modellers are still at a loss to know what they should do about real clouds as opposed to the "average cloudiness'.

John Maddox 